\title{
Depression of Elasticity of Kamaboko Induced by Pregelatinized Starch
}

\author{
Eiji Niwa,* Noriyasu Ogawa,* and Satoshi Kanoh* \\ (Received July 2, 1990)
}

\begin{abstract}
The reason for the depression of the elasticity of kamaboko upon the addition of pregelatinized starch was investigated. The breaking force and breaking deformation of the kamaboko from A. laska pollack frozen surimi were decreased and its expressible water was increased by increasing the amount of the pregelatinized corn, potato, and tapioca starches added and this was especially remarkable for the latter two starches. Such the depression in the elasticity was accelerated by the previous soaking of them in water immediately before their addition, but prevented by retarding their addition to the surimi during its grinding. The pregelatinized starch absorbed more water than the raw one during heating within $3 \%$ sodium chloride and its mechanical strength was decreased. Furthermore, it was observed that the pregelatinized starch existed as granules within the kamaboko.

From the results, it was proposed that the depression of the elasticity of the kamaboko upon the addition of the pregelatinized starch is due to the reduction of its mechanical strength upon the marked absorption of water during the kamaboko processing.
\end{abstract}

If the mechanical strength of starch is reduced by its alklinization and oxidization or by its mechanical treatment, its reinforcing effect on the elasticity of the kamaboko is reduced. In contrast, however, if the strength is increased by its aldehyde treatment, the effect was enhanced. From the result, Okada ${ }^{1)}$ has deduced that the mechanical strength of starch granules has a close relation with its reinforcing effect and that the water absorbing action of starch granule on its gelatinization improves the palatability and appearance of the products. Thereafter, various approaches were also made to elucidate the contribution of the starch to the fish protein network structure within the kamaboko. For example, during the compression of the kamaboko added with the starch, agreement between the actual and theoretical stresstrain response becomes less as the starch content is raised. ${ }^{2}$ For kamaboko to which starch has been added, its elasticity is weakened above $55^{\circ} \mathrm{C}$ which corresponds nearly to the gelatinized temperature of the starch, while weakened below this temperature for the kamaboko added with no starch. ${ }^{32}$ The reinforcing effect of the starch is reduced when the water content of the kamaboko added with the starch is adjusted to that of the kamaboko added with no starch. ${ }^{4}$ Kamaboko to which starch has been added are richer in the captured water observed by differential scanning calorimetry (DSC)..$^{3)}$ Furthermore, the starch pellet and shio-surimi mutually in contact are not bound at all by heating. ${ }^{\text {) }}$ From the findings, it seems certain that the starch acts as a water-absorbent within kamaboko rather than acts as a go-between for the protein network structures. If so, however, it cannot be interpreted the reason why the elasticity of kamaboko is depressed by the pregelatinized starch $^{1,7)}$ which is supposed to have high water absorbing capacity. In this paper, we describe the reason for the depression of the elasticity of kamaboko upon the addition of the pregelatinized starch.

\section{Materials and Methods}

\section{Materials and Kamaboko Preparation}

Raw and pregelatinized starches were donated by Sanei-Tohka Co. The pregelatinized straches had been dehydrated by a drum drier.

Non-salted Alaska pollack Theragra chalcogramma frozen surimi (Taiyo Gyogyo Co., SAgrade) was thawed by leaving overnight in a refrigerator, minced and ground together with $\mathrm{NaCl}$, starch, and water for $25 \mathrm{~min}$ in a cold room at $4^{\circ} \mathrm{C}$. The final concentration of $\mathrm{NaCl}$ was held at $3 \%$ of the water within the product.

* Faculty of Fisheries, Mie University, Edobashi, Tsu, Mie 514, Japan (丹羽策二，小川典愁，抑納 哲： 三重大学水産学部). 
The amount of the additives was expressed by the weight ratio to the frozen surimi according to the custom of the kamaboko industry. The resulting shio-surimi was packed into the casings (Kureha Kagakukogyo Co., Krehalon film, $2.8 \mathrm{~cm}$ diameter, $8 \mathrm{~cm}$ length) and heated at $40^{\circ} \mathrm{C}$ for $30 \mathrm{~min}$ for setting and then at $80^{\circ} \mathrm{C}$ for $30 \mathrm{~min}$ for kamaboko formation after closing both the ends of the casing. Thus obtained kamaboko was held overnight in the refrigerator.

\section{Puncture Test and Other Measurements}

The peeled kamaboko was cut into thick slices $(1.5 \mathrm{~cm}$ height) after equilibrated to room temperature and subjected to the puncture test by using a rheometer (Fudoh Kogyo Co., NRM $2010 \mathrm{~J}-\mathrm{CW}$ ) at a table speed of $6 \mathrm{~cm} / \mathrm{min}$ and a spherical plunger $(5 \mathrm{~mm}$ diameter). Breaking force and breaking deformation were read from the recording chart.

The amount of expressible water of the kamaboko was calculated from the weight-loss during compressing about $1 \mathrm{~g}$ of sliced sample put between double layers of filter paper (Toyo Roshi Co., No. $3,7 \mathrm{~cm}$ diameter) at $0.5 \mathrm{hg} / \mathrm{cm}^{2}$ for $3 \mathrm{~min}$.
Water absorbing capacity of the starch was estimated from the amount of water absorbed during heating within $2 \% \mathrm{NaCl}$. The starch $(0.5-2.0 \mathrm{~g})$ was packed in a Visking tube and heated together with $10 \mathrm{~m} l$ of $3 \% \mathrm{NaCl}$ at $40^{\circ} \mathrm{C}$ for $30 \mathrm{~min}$ and then at $80^{\circ} \mathrm{C}$ for $30 \mathrm{~min}$ in a graduated glass tube. The amount of water absorbed was measured from the volume of $\mathrm{NaCl}$ remaining in the tube.

Density of the raw and pregelatinized starches before and after heating was determined by the floating method previously applied to analyze the particle size of the heat-coagulated actomyosin. ${ }^{8)}$ The starch and 9.5 times of $3 \% \mathrm{NaCl}$ were heated at $40^{\circ} \mathrm{C}$ for $30 \mathrm{~min}$ and then at $80^{\circ} \mathrm{C}$ for $30 \mathrm{~min}$. Sucrose density gradient solution was prepared by adding each $0.3 \mathrm{~m} l$ of $50,40,30$, 20 , and $10 \%$ sucrose into a glass tube $(6 \mathrm{~mm}$ djameter, $8 \mathrm{~cm}$ length) in this order. The sample starch $(0.3 \mathrm{~m} l)$ was put on the density gradient solution and centrifuged at $3,000 \mathrm{rpm}$ for $10 \mathrm{~min}$. The density was roughly estimated from that of the density gradient solution where the starch was sedimentation-equilibrated.

The relative mechanical strength of the starch granule within the kamaboko was estimated from

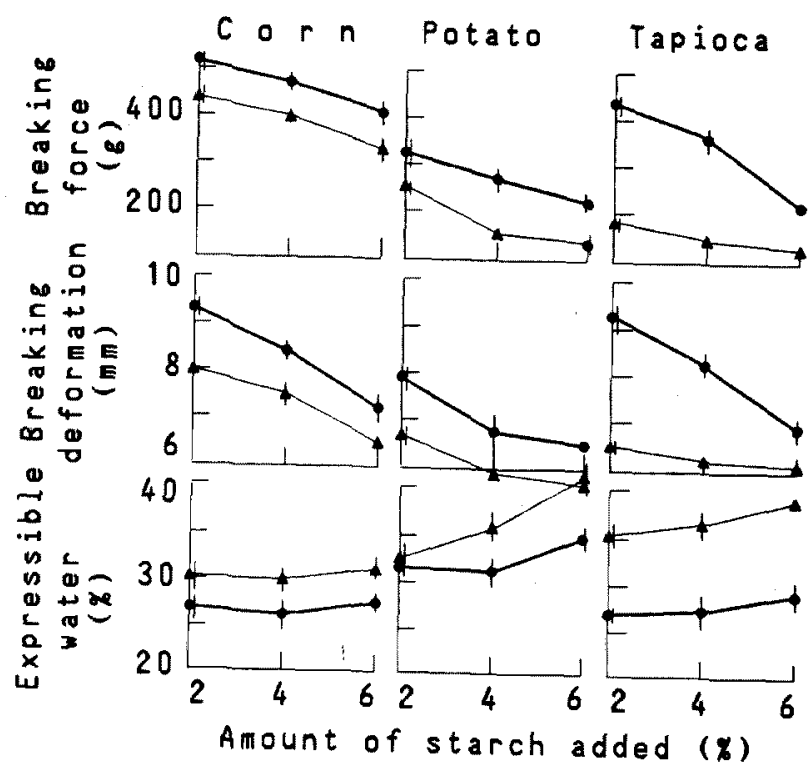

Fig. 1. Effect of the addition of the pregelatinized starch to the surimi on the elasticity of the resulting kamaboko.

- - The pregelatinized starch was added as the powdered form together with water at the beginning of grinding.

- The starch was previously soaked for $10 \mathrm{~min}$ in water to be added immediately before use. 
the breaking force of the starch gel in addition to its expressible water. Fifty grams of the starch and $3 \% \mathrm{NaCl}$ were mixed in a $50 \mathrm{~m} /$ beaker, heated at $40^{\circ} \mathrm{C}$ for $30 \mathrm{~min}$ and then at $80^{\circ} \mathrm{C}$ for $30 \mathrm{~min}$, and stood overnight in the refrigerator. A puncture test was carried out with the starch gel resulting in the beaker by using the above rheometer.

DSC of the kamaboko was carried out by using a DSC-TGA apparatus (Rigaku Denki, MJ800CK) as previously described. ${ }^{5)}$ About $25 \mathrm{mg}$ of the sample was put into an open aluminum cell (reference; empty cell). The oven temperature was raised from $25^{\circ} \mathrm{C}$ to $170^{\circ} \mathrm{C}$ at a speed of $10^{\circ} \mathrm{C} / \mathrm{min}$ under the flow of helium. The $R_{105}$ value was calculated from the DSC curve according to the method of Akahane. ${ }^{\text {) }}$

In order to examine the state of the pregelatinized starch within the kamaboko, micrographs were taken on $10 \mu \mathrm{m}$ thickness of the sliced kamaboko after stained in $I_{2} / \mathrm{KI}$ for $1 \mathrm{~h}$.

\section{Result and Discussion}

Control kamaboko added with no pregelatinized starch showed $600 \pm 44 \mathrm{~g}, 10.9 \pm 0.6 \mathrm{~mm}$, and
$25.7 \pm 1.0 \%$, respectively, in the breaking force, breaking deformation and amount of expressible water. Figure 1 shows the effect of the pregelatinized corn, potato, and tapioca starches on the elasticity of the resulting kamaboko. Each starch was added to the surimi as two forms, powdered and soaked forms. The starch powder was added together with water at the beginning of the grinding in the former, while previously soaked for $10 \mathrm{~min}$ in the water to be added immediately before use in the latter. As shown in the top and middle of Fig. 1, the breaking force and breaking deformation of the kamaboko were decreased with increasing the amount of the pregelatininzed starch added. This tendency was remarkable for the potato and tapioca starches, but not so for the corn starch. As shown in the bottom of Fig. 1, the amount of the expressible water was increased with increasing the amount of the pregelatinized starch added. It was confirmed also from the result that the elasticity of the kamaboko is depressed by the addition of the pregelatinized starch. Furthermore, such the depression was accelerated by the previous soaking of the pregelatinized starch in water immediately before the addition. Thus

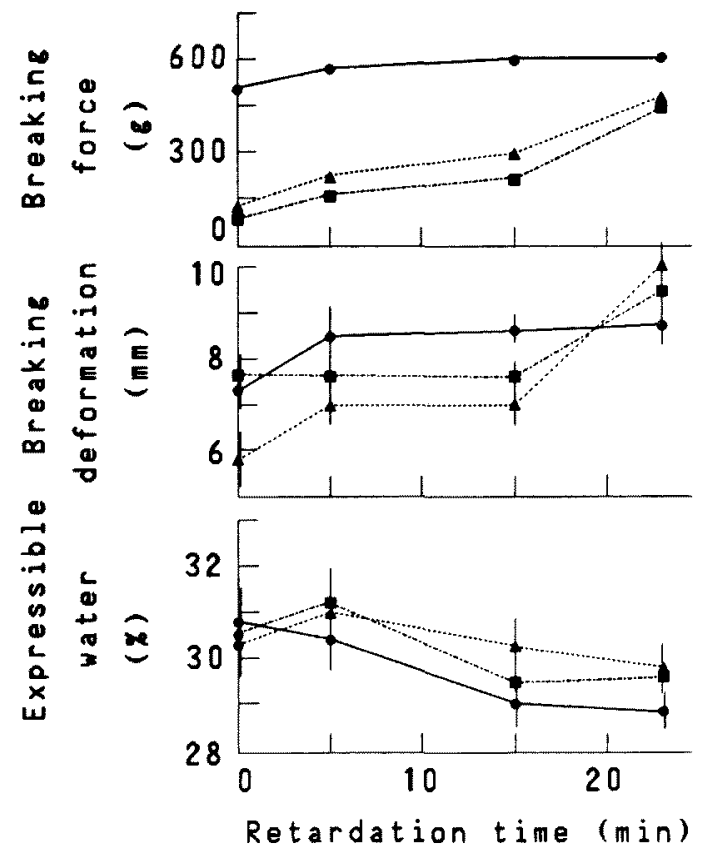

Fig. 2. Effcet of the retardation of the addition of the pregelatinized starch to the surimi during its grinding on the elasticity of the resulting kamaboko.

-- corn starch; - - - , potato starch; - - tapioca starch. Retardation time was expressed by that after the starting of the grinding. 


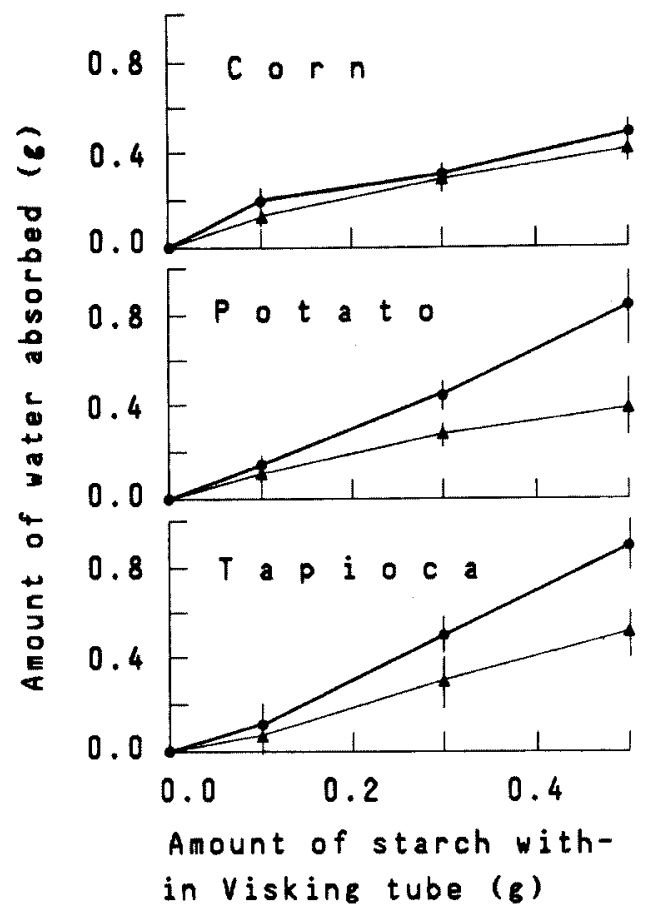

Fig. 3. Comparison of water absorbing capacity between the raw and pregelatinized starches heated within Visking tube at $40^{\circ} \mathrm{C}$ for $30 \mathrm{~min}$ and then at $80^{\circ} \mathrm{C}$ for $30 \mathrm{~min}$.

--, pregelatinized starch; - - , raw starch.

the depression may be due to that the pregelatinized starch absorbs much water during grinding of the surimi.

Figure 2 shows the effect of retardation of the addition of the pregelatinized starch to the surimi during its grinding on the elasticity of the kamaboko. The decrease in the breaking force and breaking deformation and the increase in the expressible water upon the addition of the pregelatinized starch were somewhat prevented when its addition was retarded. Such the effect of the retardation on the elasticity was, however, not so remarkable for the pregelatinized corn starch, by which the depression of the elasticity was not so remarkable. This result also suggests that the depression is due to the absorption of water by the pregelatinized starch during the grinding.

Figure 3 shows the comparison of water absorbing capacity between the raw and pregelatinzed starches heated within $3 \% \mathrm{NaCl}$. The pregelatinized starch was higher than the raw starch in
Table 1. Comparison of the density between the raw and pregelatinized starches before and after heating

\begin{tabular}{lcc}
\hline \multirow{2}{*}{ Starch } & \multicolumn{2}{c}{ Density at $25^{\circ} \mathrm{C}\left(\mathrm{g} / \mathrm{cm}^{3}\right)$} \\
\cline { 2 - 3 } & Before heating & After heating \\
\hline Raw & $>1.25$ & $>1.25$ \\
Corn & $>1.25$ & $>1.25$ \\
Potato & $>1.25$ & 1.24 \\
Tapioca & & \\
Pregelatinized & 1.24 & 1.24 \\
Corn & 1.24 & 1.19 \\
Potato & 1.24 & 1.22 \\
Tapioca & & \\
\hline
\end{tabular}

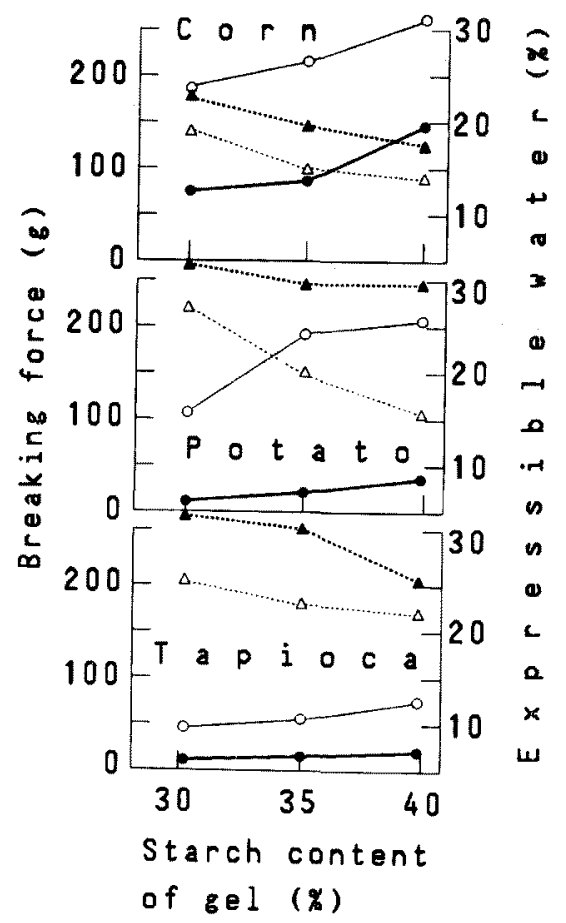

Fig. 4. Comparison of the mechanical strength between the raw and pregelatinized starch gels estimated from their breaking force in addition to the amount of expressible water.

Pregelatinized starch: - - breaking force; - $\mathbf{-}-$, expressible water.

Raw starch: $-\mathrm{O}-$, breaking force; $-\Delta-$, expressible water.

the capacity and this was especially remarkable in the potato and tapioca starches. The absorption of water may be induced also during heating of the shio-surimi.

Table 1 shows the comparison of the density 
between the raw and pregelatinized starches before and after heating under the same condition as that of the kamaboko preparation. The pregelatinized starch was only a little lower than the raw starch in the density before heating but considerably lowered by heating except for the pregelatinized corn starch. This result also suggests that the pregelatinized starch has a tendency to absorb more water within the shio-surimi during the heating process. Also in raw starch, the potato and tapioca starches were found to swell more largely than the corn starch when they were heated at $70^{\circ} \mathrm{C} .{ }^{10)}$

Figure 4 shows the comparison of the mechanical strength between the raw and pregelatinized starch gels. The pregelatinized starch gel was markedly lower than the raw starch gel in the breaking force and higher in the expressible water, which was more remarkable in the potato and tapioca starches than in the corn starch. From the result, it is suggested that the mechanical strength of the former two starches is markedly reduced within the kamaboko and that they easily ooze out water irrespective of their higher water absorbing capacity.

From the DSC curves of the kamaboko added with/without the pregelatinized starch, it was clarified that a peak appeared around $80^{\circ} \mathrm{C}$ and that the $R_{105}$ value was 47,37 , and $44 \%$ for the kamaboko added with $6 \%$ of the pregelatinized corn, potato, and tapioca starches, respectively, while $54 \%$ for the kamaboko added without starch. This suggests that the amount of captured water is partionlarly small for kamaboko to which pregelatinized potato and tapioca starches have been added.

Figure 5 shows the micrographs of the shiosurimi and kamaboko added with $6 \%$ of the pre-

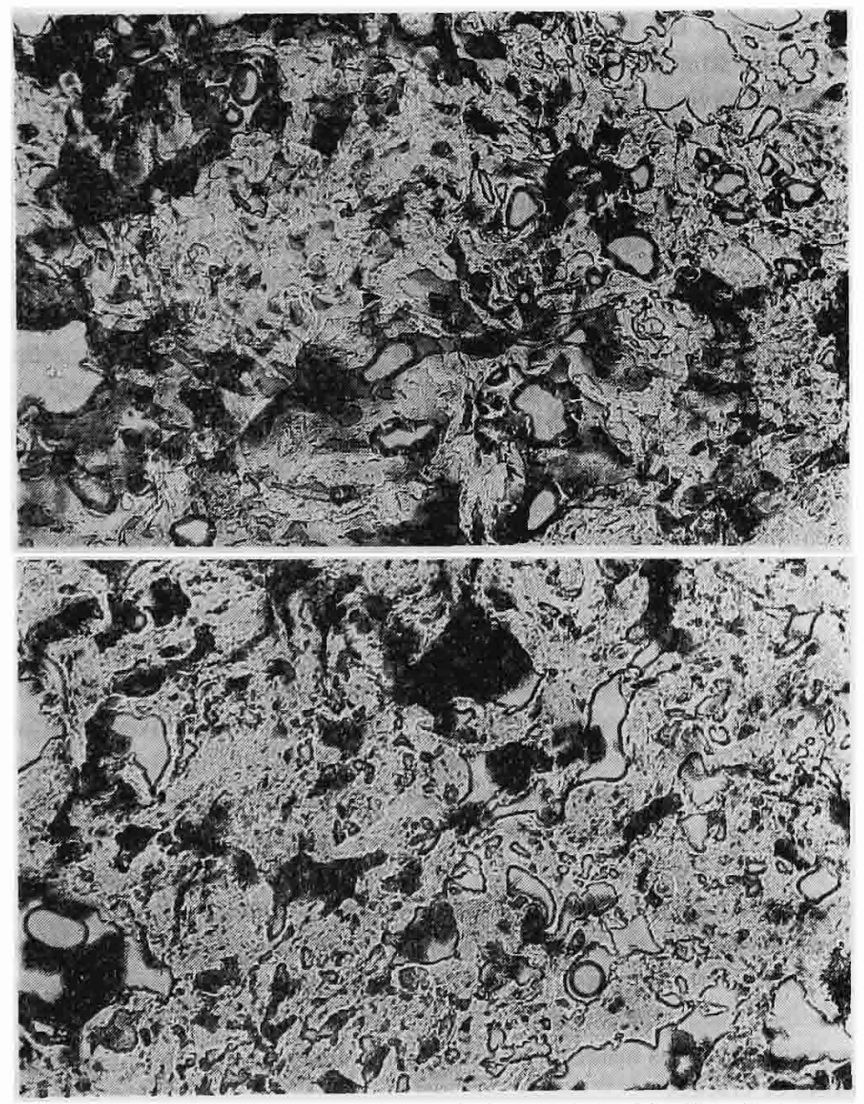

Fig. 5. Micrographs of the shio-surimi and kamaboko added with $6 \%$ of the pregelatinized tapioca starch.

Top, shio-surimi; bottom, kamaboko $(\times 100)$. 
gelatinized tapioca starch. Little difference was detected between them in the state of the starch observable as black spots, suggesting that the pregelatinized starch exists as granule also within the kamaboko.

Considering the result that the elasticity of the kamaboko was remarkably depressed by the pregelatinized potato and tapioca starches which showed especialiy high water absorbing capacity, the depression upon the addition of them would be due to their absorption of water during the grinding and heating processes. Although the pregelatinized starch exists as granules within the kamaboko, their mechanical strength would be remarkably decreased by hydration. Conversely, the mechanical strength of the surrounding protein matrix may be increased by dehydration. The authors reported previously that the kamaboko was weaekned due to stress concentration* if the dispersion of the protein matrixes became unhomogeneous within it. ${ }^{11)}$ Similarly, the kamaboko would be weakened if the protein matrixes having higher mechanical strength and the pregelatinized starch granules having lower mechanical strength are repeatedly dispersed.

For the purpose of screening of new gelling substances, it is needed to notice the balance between the water absorbing capacity of the object and its mechanical strength when it is heated within water.

The study was partly supported by a grant of Ajinomoto Co., Ltd.

\section{References}

1) M. Okada: Bull. Tokäi Reg. Fish. Res. Lab., No. 36, 21-126 (1963).

2) I. Takagi and W. Simidu: Nippon Suisan Gakkaishi, 38, 471-474 (1972).

3) M. Hamada and Y. Inamasu: Nippon Suisan Gakkaishi, 50, 537-540 (1984).

4) N. Iso, H. Mizuno, T. Saito, C.-Y. Lin, T. Fujita, and E. Nagahisa: Nippon Suisan Gakkaishi, 51, $485-488$ (1985).

5) E. Niwa, T.-T. Wang, S. Kanoh, and T. Nakayama: Nippon Suisan Gakkaishi, 54, 2139-2142 (1988).

6) E. Niwa, T. T. Wang, S. Kanoh, and T. Nakayama: Nippon Suisan Gakkaishi, 54, 989-992 (1988).

7) J.-M. Kim and C.-M. Lee: J. Food Sci., 52, 722725 (1987).

8) E. Niwa, S. Kanoh, and T. Nakayama: Nippon Nogeikagaku Kaishi, 60, 279-285 (1986).

9) T. Akahane, S. Chihara, Y. Yoshida, T. Tsuchiya, S. Noguchi, H. Ookami, and J. J. Matsumoto: Nippon Suisan Gakkaishi, 47, 105-111 (1981).

10) T. Yamashita and T. Yoneda: Nippon Shokuhin Kogyo Gakkaishi, 36, 214-221 (1989).

11) E. Niwa and T. Nakayama: Nippon Suisan Gakkaishi, 50, 1945-1948 (1984).

* A local increase in the stress inside an object, usually induced by an abrupt change in shape of a member, such as notches or crackes. 